$$
\begin{aligned}
& \text { ANh/CHM/CP-93624 } \\
& \text { CONF- } 97 / 029-
\end{aligned}
$$

The Use of Reactive Ion Sputtering to Produce Clean Germanium Surfaces in a Carbon Rich Environment - An Ion Scattering Study*

V. S. Smentkowski1†, J. C. Holecek 2 , J. A. Schultz ${ }^{2}$, A. R. Krauss ${ }^{1}$, and D. M. Gruen ${ }^{1}$

1Materiais Science and Chemistry Divisions, Argonne National Laboratory, Argonne, Il 60439 2Ionwerks, Houston, TX 77005

tCurrent Address: GE-CRD, P.O. Box 8, Schenectady, NY 12301

submitted for publication in the

BEC

Proceedings of the $44^{\text {th }}$ National Symposium of

Nov 181997

the American Vacuum Society

San Jose, California

OSTI

October 20-24, 1997
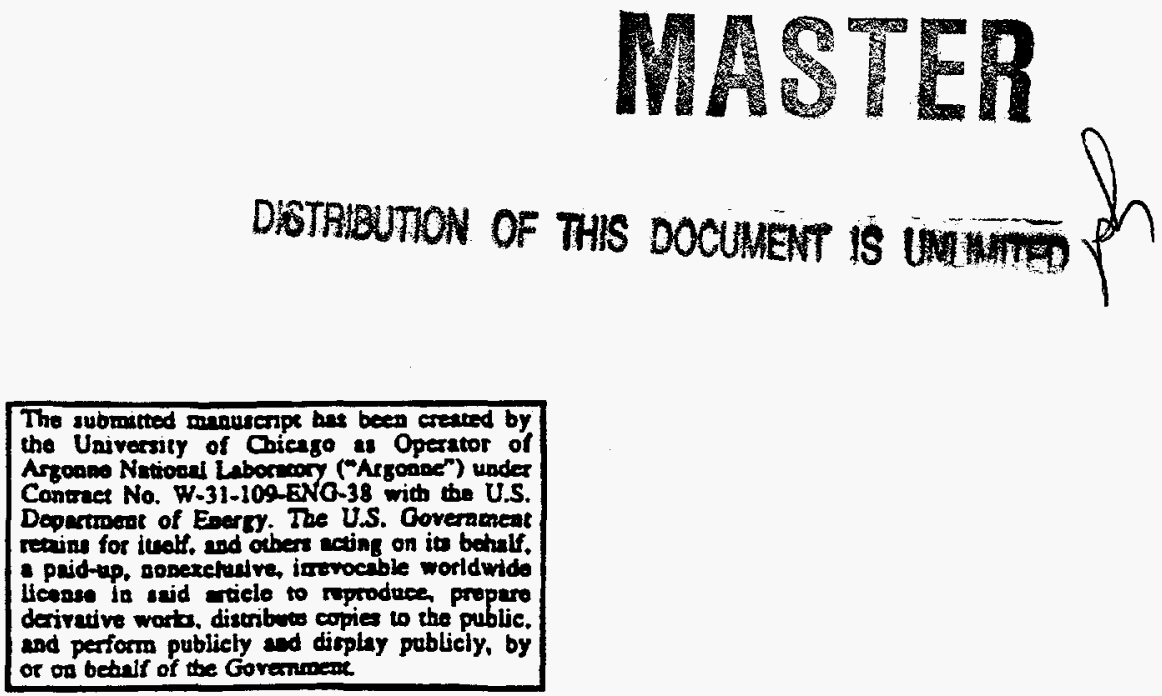

*Work supported by the U.S. Department of Energy, BES-Materials Sciences, under Contract

W-31-109-ENG-38 and CRADA \#C9405001 with Ionwerks, Houston, Texas. 


\section{DISCLAIMER}

This report was prepared as an account of work sponsored by an agency of the United States Government. Neither the United States Government nor any agency thereof, nor any of their employees, makes any warranty, express or implied, or assumes any legal liability or responsibility for the accuracy, completeness, or usefulness of any information, apparatus, product, or process disclosed, or represents that its use would not infringe privately owned rights. Reference herein to any specific commercial product, process, or service by trade name, trademark, manufacturer, or otherwise does not necessarily constitute or imply its endorsement, recommendation, or favoring by the United States Government or any agency thereof. The views and opinions of authors expressed herein do not necessarily state or reflect those of the United States Government or any agency thereof. 


\section{DISCLAMVIER}

Portions of this document may be illegibie in electronic image products. Imiges are produced from the best available original docementert. 
GE_AVS.doc;

Submitted to:

J. Vac. Sci. Technol.

Date:

October 7, 1997

Abstract Number: 898

Program Number: $E M+S S-T u A 10$

\title{
The Use Of Reactive Ion Sputtering To Produce Clean Germanium Surfaces In A Carbon Rich Environment - An Ion Scattering Study
}

\author{
V. S. Smentkowski ${ }^{\dagger}$, J.C. Holecek ${ }^{2}$, J.A. Schultz ${ }^{2}$, A. R. Krauss 1 , and D. M. Gruen ${ }^{1}$ \\ ${ }^{1}$ Argonne National Laboratory, Materials Science and Chemistry Divisions, 9700 S. Cass Ave, \\ Argonne, IL 60349 \\ 2Ionwerks, 2472 Bolsover, Suite 255, Houston, TX 77005

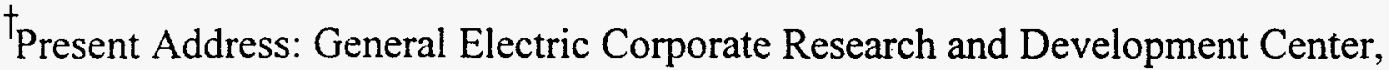 \\ Characterization and Environmental Technology Laboratory, Schenectady, NY 12301
}

\begin{abstract}
We have used the ion spectroscopic techniques of direct recoil spectroscopy (DRS) and mass spectroscopy of recoiled ions (MSRI) to demonstrate that low energy reactive ion sputtering of $\mathrm{Ge}$ is capable of removing surface impurities such as carbon. The experiments were performed in a vacuum chamber maintained at $3.5 \times 10^{-7}$ Torr. At these pressures, physical sputtering using noble gas is not effective for cleaning Ge surfaces as carbon re-deposits onto the surface. In this paper, we demonstrate that reactive sputtering of Ge using $4.0 \mathrm{keV}$ nitrogen at a $\mathrm{Ge}$ surface temperature of $\sim 740 \mathrm{~K}$ and above removes surface carbon and deposits nitrogen on the Ge surface. Heating the nitrogen exposed Ge surface to above $\sim 880 \mathrm{~K}$ results in the desorption of nitrogen and generates an atomically clean Ge surface, under poor vacuum conditions.
\end{abstract}




\section{INTRODUCTION}

Germanium has been proposed as a material for metal oxide semiconductor (MOS) applications since the mobility of holes in germanium is greater than the hole mobility in most other semiconductors [1-4]. Additionally, the hole and electron mobilities are much less disparate than in other semiconductors, particulary at low temperatures. For example, at $77 \mathrm{~K}$ the electron and hole mobilities in lightly doped germanium samples exceed $20,000 \mathrm{~cm}^{2} / \mathrm{V} \mathrm{s}$ [24]. Previous studies of germanium/insulator systems involved the use of native insulators such as $\mathrm{GeO}_{2}$ [2-5]. Although $\mathrm{GeO}_{2}$ can form an interface with germanium that exhibits good electrical properties, it is water soluble [4,5]. The absorption of water from the air results in the degradation of the interfacial electrical properties, making $\mathrm{GeO}_{2}$ undesirable from a device processing standpoint. It has been demonstrated that the nitridation of the Ge surface produces a germanium/insulator system that exhibits good electrical properties and is not water soluble [2.5,6]. Others have used molecules such as $\mathrm{NH}_{3}$ [6-11], $\mathrm{N}_{2} \mathrm{H}_{4}$ [6], $\mathrm{HN}_{3}$ [6], NO[9, 12-15], and $\mathrm{N}_{2} \mathrm{O}[14,16,17]$ for the nitridation of Ge. Unfortunately, these molecules decompose to produce a mixed surface phase consisting of $\mathrm{N}$ and $\mathrm{H}[6-11]$ or $\mathrm{O}[9,12-17]$ depending on the molecule used.

Others have demonstrated that both hydrogen and oxygen are easily removed from the Ge surface by heating to $\sim 780 \mathrm{~K}[6,8,14,15,17-22]$. It has also been demonstrated that physical (noble gas) sputtering under ultra-high vacuum (UHV) conditions is needed to remove surface carbon $[7.9-11,14,15,17,19,21-24]$. Physical sputtering at pressures greater than $\sim 10^{-8}$ Torr results in carbon redeposition onto the Ge surface; as a result physical sputtering can not be used to generate a clean surface under typical surface processing and film growth conditions. We are currently using low energy nitrogen sputtering to study the nitridation of Ge without the codeposition of other species. During our initial studies, we have observed that reactive ion sputtering of Ge surfaces, using $4.0 \mathrm{keV}$ nitrogen at a temperature of $\sim 740 \mathrm{~K}$ or greater. efficiently removes surface carbon and deposits nitrogen onto the Ge surface -- even under poor vacuum conditions. Heating the nitrogen exposed Ge surface to above $880 \mathrm{~K}$ results in the removal of surface nitrogen and generates an atomically clean Ge surface.

\section{EXPERIMENTAL}

In direct recoil spectroscopy (DRS), a pulsed ion beam with a few $\mathrm{keV}$ of energy strikes the surface at a glancing angle $[25,26]$. Surface atoms are ejected in the forward scattering 
direction and the time-of-flight (TOF) of the scattered particles (ions and/or neutrals) is measured $[25,26]$. For an ideal binary collision, each mass has a unique energy dictated by the scattering angle, the mass of the primary beam, and the energy of the primary beam $[25,26]$. In reality, the collisions are not ideal and as a result, each mass has an energy distribution which broadens the DRS features and degrades the resolution. The ionic fraction of the recoiled particles can be time-refocused using an analyzer which forces all ions of a given mass to arrive at the detector simultaneously -- regardless of their energy [25-27]. The use of a time-refocusing analyzer drastically improves the resolution of the recoiled ions and is referred to as mass spectroscopy of recoiled ions (MSRI) $[25,26]$.

The experiments reported below were performed in the ion pumped UHV chamber shown in Figure 1. The chamber was intentionally maintained at a pressure of $3.5 \times 10^{-7} \mathrm{Torr}$; the main gas phase constituents were water and hydrocarbon species. A $10 \mathrm{keV}$ pulsed potassium ion beam, with a pulsed current of $\sim 1 \mathrm{nA}$ (corresponding to a beam dose of $\sim 10^{9} \mathrm{~K}^{+} / \mathrm{cm}^{2}$ s), was used for the experiments reported here. Two MSRI analyzers, a Poschenreider sector analyzer [28], and a floating reflectron analyzer (described in detail elsewhere [27, 29]), were positioned at forward scattering angles of 35 degrees and 74 degrees respectively on the chamber (see Figure 1). Two linear time of flight detectors were positioned at scattering angles of 15 degrees and 35 degrees for direct recoil spectroscopy (DRS) [30-32] measurements. The 15 degree DRS sampled both the ionic and neutral species, while the 35 degree DRS sampled only the neutral species (the ion fraction was diverted into the Poschenreider sector analyzer). DRS has recently been used to study Si/Ge growth mechanisms [33.34]. An Ionwerks time to digital converter (Model TDC.44) with a digitizing resolution of $0.8 \mathrm{nsec}$ was used to collect data into all four channels simultaneously during a single experiment. For all of the measurements reported in this paper. data acquisition times of 15 minutes were used (unless noted otherwise) and the $\mathrm{Y}$ axis intensity corresponds to the total integrated counts (during the $15 \mathrm{~min}$. scan). Successive spectra are offset on the $\mathrm{Y}$ axis for clarity.

Reactive ion sputtering was performed using a SPECS (Model IQE-12/38) sputter ion gun operating at $+.0 \mathrm{keV}$. Reactive ion sputtering produces a mixture of $\mathrm{N}^{+} . \mathrm{N}_{2}{ }^{-}$and $\mathrm{N}_{3}{ }^{+}$; we did not characterize the composition of the beam. Nitrogen exposures were calculated using the sputtering time and the current measured in a $390 \mu \mathrm{m}$ diameter faraday cup which could be translated into the position of the sample. 
Experiments were performed using three different Ge samples. The sample used for most of the experiments reported here did not have any metal contaminants. One Ge sample was contaminated with $\mathrm{Na}, \mathrm{Al}, \mathrm{Cr}$, and $\mathrm{Fe}$ (see Figure 8), while another was contaminated with $\mathrm{Ti}$ (data not shown) - similar results were obtained for each of the three samples indicating that reactive ion sputtering may be useful for the cleaning of $\mathrm{Na}, \mathrm{Al}, \mathrm{Cr}, \mathrm{Fe}$ and/or $\mathrm{Ti}$ samples as well. The sample temperatures were measured using an optical pyrometer which was corrected for the emissivity of $\mathrm{Ge}$ and the chamber window. The repeatability of the measurements provides an uncertainty of $+/-15 \mathrm{~K}$ in the temperatures reported here.

\section{RESULTS}

Figure 2 shows MSRI spectra obtained as a function of heating temperature. Heating to $-740 \mathrm{~K}$ reduces the $\mathrm{H}, \mathrm{C}$, and $\mathrm{O}$ yields. Heating to $880 \mathrm{~K}$ depleted the $\mathrm{H}$ and $\mathrm{O}$; the thermal stability of $\mathrm{H}$ and $\mathrm{O}$ measured here agrees well with the thermal stability measured by others [6.8.14,15,17,18-22,35-37]. A significant amount of carbon remained on the Ge surface following heating to $880 \mathrm{~K}$, a result previously reported by others [7,9-11,14,15,17,19,21-24]. The increased noise level for spectrum $\mathrm{C}$ ( $880 \mathrm{~K}$ heating) is an artifact induced by the sample heating configuration used in this work. Despite the increased noise level in spectrum (C) of Figure 2, it is clear that a large amount of carbon remains on the Ge surface following heating to $880 \mathrm{~K}$.

The Ge sample was then cooled to $740 \mathrm{~K}$ and the MSRI spectral intensities were monitored until they reached steady state values. Next, the vacuum chamber was backfilled with molecular nitrogen ( $\mathrm{P} \sim 7.0 \times 10^{-7}$ Torr $\mathrm{N}_{2}$ ). Spectrum (A) of Figure 3 shows a MSRI spectrum obtained under steady state conditions in the molecular nitrogen environment, both hydrogen and carbon are present on the Ge surface. Spectra B to D of Figure 3 show representative MSRI spectra obtained as a function of $4.0 \mathrm{keV} \mathrm{N}$ exposure at $740 \mathrm{~K}$. The changes in $\mathrm{H}$ (open circle solid line), $\mathrm{C}$ (open triangle - dashed line), and $\mathrm{N}$ (filled inverted triangle - dotted line) MSRI yield for each $\mathrm{N}$ exposure measured are plotted in Figure 4. The data of Figures 3 and 4 show that as the $\mathrm{N}$ exposure increases, the surface concentration of both $\mathrm{H}$ and $\mathrm{C}$ decrease.

The small $\mathrm{H}$ and $\mathrm{C}$ intensities observed following a $\mathrm{N}$ exposure of $24.5 \times 10^{15} \mathrm{~cm}^{-2}$ in Figures 3 and 4 are not observed if the above experiment is repeated using 1.0 minute spectral acquisition times (instead of the 15 minute spectral acquisition time used here). These results indicate that the small $\mathrm{H}$ and $\mathrm{C}$ signals result from the adsorption of hydrocarbon species onto 
the $\mathrm{Ge}$ surface. In order to prove this point, the Ge sample was maintained at $740 \mathrm{~K}$ in molecular nitrogen for extended time periods following a $\mathrm{N}$ exposure of $24.5 \times 10^{15} \mathrm{~cm}^{-2}$. The changes in the $\mathrm{H}$ (open circles - solid line), $\mathrm{C}$ (open triangle - dashed line), and $\mathrm{N}$ (filled inverted triangle - dotted line) MSRI intensities as a function of time are presented in Figure 5. For these experiments, a data acquisition time of 1.0 minute was used. Figure 5 illustrates that as the Ge surface is maintained at $740 \mathrm{~K}$ in molecular nitrogen, the $\mathrm{H}$ and $\mathrm{C}$ intensities increase at a similar rate - indicating that hydrocarbon species are adsorbing onto the Ge surface. It is noted that the nitrogen concentration tracks with the carbon concentration, we will return to this observation in section IV.

The small amount of $\mathrm{H}, \mathrm{C}$, and $\mathrm{N}$ on the Ge surface following a $\mathrm{N}$ exposure of $24.5 \times 10^{15}$ $\mathrm{cm}^{-2}$ at $740 \mathrm{~K}$ (Figures 3 and 4), or residing in molecular nitrogen for extended time periods following the termination of $\mathrm{N}$ sputtering at $740 \mathrm{~K}$ (Figure 5), could be removed by heating the Ge sample to $880 \mathrm{~K}$, as shown in spectrum A of Figure 6. Spectrum B of Figure 6 shows that $\mathrm{H}$, $\mathrm{C}$, and $\mathrm{N}$ are not detected on the Ge sample after cooling to $800 \mathrm{~K}$. Spectrum $\mathrm{C}$ of Figure 6 shows that both $\mathrm{H}$ and $\mathrm{C}$ are detected on the Ge sample following cooling to $760 \mathrm{~K}$. Both the $\mathrm{H}$ and $\mathrm{C}$ could be removed by re-heating to $880 \mathrm{~K}$. It is of importance to note that nitrogen is not detected in Spectrum $\mathrm{C}$ of Figure 6. We shall return to this point in section IV

The $4.0 \mathrm{keV}$ nitrogen sputtering experiments were repeated at a Ge surface temperature of $810 \mathrm{~K}$, and the results are plotted in Figure 7 . At $810 \mathrm{~K}$, no $\mathrm{H}$ or $\mathrm{O}$ is detected on the Ge surface prior to $\mathrm{N}$ ion bombardment, in accord with the thermal stability of $\mathrm{H}$ and $\mathrm{O}$ reported in the literature [6.8.14,15,17,18-22,35-37]. Comparing the data of Figure 4 (740 K) and Figure 7 (810 $\mathrm{K}$ ) illustrates that the rate of $\mathrm{C}$ removal is enhanced at higher temperatures. At $810 \mathrm{~K}$, all of the carbon is removed from the Ge surface following a $\mathrm{N}$ exposure of $1.6 \times 10^{16} \mathrm{~cm}^{-2}$ (background hydrocarbon species do not re-adsorb) - only $\mathrm{N}$ is detected on the Ge surface. Heating the nitrogen exposed Ge surface to $880 \mathrm{~K}$ depletes the surface nitrogen and produces an atomically: clean Ge surface. The thermal stability of nitrogen on Ge reported here is in agreement with the results obtained in other laboratories [6,9.14.15]. The clean Ge surface could be maintained at temperatures of $810 \mathrm{~K}$ to $900 \mathrm{~K}$ without additional nitrogen bombardment.

\section{DISCUSSION}

The MSRI spectra shown in Figure 2 illustrate that heating to $880 \mathrm{~K}$ is not able to remove carbon from the Ge surface. Physical (noble gas) sputtering under ultra-high vacuum 
conditions has been used by others to remove the surface carbon $[7,9-11,14,15,17,19,21-24]$. Physical sputtering in a carbon rich environment $\left(\sim 10^{-8}\right.$ Torr) results in carbon redeposition onto the surface, and hence physical sputtering can not be used to generate clean surfaces under conditions used in many surface processing and film growth systems. In this work, we have shown that reactive ion sputtering (using $4.0 \mathrm{keV} \mathrm{N}$ ) is able to remove surface carbon from Ge at a surface temperature of $740 \mathrm{~K}$ or greater. The reactive ion sputtering deposits nitrogen onto and below the Ge surface. Heating to $\sim 880 \mathrm{~K}$ removes the nitrogen, and generates an atomically clean Ge surface. The ion spectroscopic techniques used in this study did not allow us to identify the carbon containing species leaving the Ge surface. We also did not investigate whether lower energy $\mathrm{N}$ sputtering is capable of removing surface $\mathrm{C}$. Researchers elsewhere were informed of the results reported here and have demonstrated that low energy $(\sim 10 \mathrm{eV}) \mathrm{N}^{+}$ions generated via an electron cyclotron resonance (ECR) plasma also efficiently removes surface $\mathrm{C}$ from $\mathrm{Ge}$ surfaces at a temperature of $\sim 700 \mathrm{~K}[38]$.

Throughout this work, the nitrogen MSRI yield was the greatest when the carbon yield was large (i.e., at a $\mathrm{N}$ exposure of $0 \mathrm{~cm}^{-2}$ at $740 \mathrm{~K}$ [Figures 3 and 4] and $810 \mathrm{~K}$ [Figure 7]). Following the removal of most of the carbon (i.e., a $\mathrm{N}$ exposure of $5.88 \times 10^{15} \mathrm{~cm}^{-2}$ at $740 \mathrm{~K}$ [Figures 3 and 4] and a $\mathrm{N}$ exposure of $\sim 3 \times 10^{15} \mathrm{~cm}^{-2}$ at $810 \mathrm{~K}$ [Figure 7]) the nitrogen yield reached steady state values. The steady state nitrogen yields obtained at $740 \mathrm{~K}$ (Figure 4) and $810 \mathrm{~K}$ (Figure 7) were essentially the same, indicating that the nitrogen concentration on Ge was temperature independent. This is not surprising when one recalls that nitrogen is thermally stable on Ge up to $\sim 840 \mathrm{~K}[6,9,14,15]$. Figure 5 shows the changes in the $\mathrm{H}, \mathrm{C}$, and N MSRI yields as a function of time following the last $\mathrm{N}$ exposure at $740 \mathrm{~K}$. It is noted that the $\mathrm{N}$ yield tracked the $C$ yield. Furthermore, when only a small amount of $\mathrm{C}$ was detected on the $\mathrm{Ge}$ sample following cooling to $760 \mathrm{~K}$ (Spectrum $\mathrm{C}$ of Figure 6 ) no nitrogen was detected. The data presented in Figures 4 to 7 illustrate that the large nitrogen yield correlates with the carbon yield and indicates that surface nitrogen is stabilized by carbon.

The MSRI spectra shown in Figures 2 and 3 illustrate that the $\mathrm{Ge}^{+2} / \mathrm{Ge}^{+1}$ ratio increases as the Ge surface is cleaned. If the clean Ge surface is allowed to remain at temperatures below $\sim 780 \mathrm{~K}$. the Ge surface slowly recontaminates with carbon and hydrogen and the $\mathrm{Ge}^{+2} / \mathrm{Ge}^{+1}$ ratio decreases (as shown in Figure 6). Since the MSRI ions are ejected from the surface with a large velocity [29], they are not very sensitive to charge neutralization with the surface. The MSRI data reported here shows that the MSRI ion yield changes by a small amount as the oxidation 
state of the surface changes [39]. In comparison, the much lower velocity secondary ions detected using secondary ion mass spectroscopy (SIMS) are very susceptible to charge neutralization with the surface. In SIMS, the ion yield changes by orders of magnitude as the oxidation state of the sample changes [40-42].

The experiments reported above were repeated using two additional Ge samples. One of these samples was contaminated with $\mathrm{Na}, \mathrm{Al}, \mathrm{Cr}$, and $\mathrm{Fe}$, while the other was contaminated with Ti. Figure 8 shows MSRI spectra (top panel), 35 degree neutral only DRS (middle panel), and 15 degree ion plus neutral DRS (bottom panel) of a Ge sample contaminated with $\mathrm{Na}, \mathrm{Al}, \mathrm{Cr}$, and Fe following: (A) heating to $780 \mathrm{~K}$ (top spectrum) and, (B) a N exposure of $5.0 \times 10^{15} \mathrm{~cm}^{-2}$ at 780 $\mathrm{K}$. C and $\mathrm{N}$ are fully resolved in the MSRI spectra; however the degraded resolution of DRS (middle and lower panels) does not allow for the complete separation of carbon and nitrogen [spectra (A)]. As a result, the nitrogen signal is buried in the long time of flight tail of carbon -complicating the positive identification of nitrogen. Upon depletion of most of the carbon, nitrogen is clearly observed in the DR spectra [spectra (B)]. Despite the degraded resolution of DRS (vs. MSRI), it is worth noting the total elemental yield (ions plus neutrals) can be measured using DRS. DRS can therefore be used to convert the simultaneously collected MSRI (ion only) yield to true surface concentration - as discussed in detail elsewhere [26].

It is of interest to note that $\mathrm{Cr}$ and $\mathrm{Fe}$ are detected in the MSRI and 35 degree DR spectra. however these species are not detected in the 15 degree DR spectra. At low angles, the surface specificity of DRS increases. These results indicate that the $\mathrm{Cr}$ and Fe are subsurface, and hence are not detected in the 15 degree DRS data channel. Additional experiments (using ion scattering spectroscopy, a small spot XPS, and scanning AES) are underway in order to check the hypothesis that $\mathrm{Cr}$ and $\mathrm{Fe}$ are subsurface.

The data presented in Figure 8 illustrates that being able to simultaneously monitor multiple data channels during a single experiment provides information that would not be possible if only one data channel was monitored. It is of importance to note that $\mathrm{N}$ ion bombardment was able to deplete carbon from the Ge sample contaminated with $\mathrm{Na}$. $\mathrm{Al}$. Cr. and $\mathrm{Fe}$ - as shown in Figure 8 This observation indicates that reactive $\mathrm{N}$ sputtering may be a useful method for cleaning other (e.g., Na. Al, Cr. Fe, and Ti) surfaces.

The $4.0 \mathrm{keV} \mathrm{N}$ ions used in the experiments reported here penetrates into the Ge sample. Experiments were not performed in order to determine the implantation depth of nitrogen. The 
outward diffusion of subsurface nitrogen plays some role in the cleaning processes reported here.

\section{SUMMAEY AND CONCLUSIONS}

The use of physical sputtering to remove $\mathrm{C}$ is not feasible in a carbon rich environment as carbon from the background re-deposits onto the surface. We have used the ion spectroscopic techniques of DRS and MSRI to demonstrate that reactive ion sputtering of Ge, using $4.0 \mathrm{keV}$ nitrogen, is capable of removing surface $C$ in a carbon rich environment at temperatures of $740 \mathrm{~K}$ and above. Reactive $\mathrm{N}$ sputtering deposits $\mathrm{N}$ on (and under) the germanium surface; heating to $880 \mathrm{~K}$ depletes the surface $\mathrm{N}$ and generates an atomically clean $\mathrm{Ge}$ surface. Similar results were obtained for the three different Ge samples used in this work, despite the fact that metal contaminants were present on two of the Ge samples -- indicating that reactive $\mathrm{N}$ ion sputtering may be a useful method to clean other surfaces under poor vacuum conditions.

Work supported by the U.S. Department of Energy, BES - Materials Sciences, under contract w31-109-eng-38 and CRADA C9405001.

\section{FIGURE CAPTIONS}

Figure 1. Schematic of the vacuum chamber used in this work. The two MSRI analyzers and the two DRS detectors are illustrated. For clarity, only part of the alkali ion beam source is shown.

Figure 2. MSRI spectra of Ge obtained using the 74 degree reflectron analyzer at: (A) $300 \mathrm{~K}$. (B) $740 \mathrm{~K}$, and (C) $880 \mathrm{~K}$. The higher noise level for spectrum (C) is an artifact due to the heater used in this work. This figure demonstrates that heating alone is not capable of removing $\mathrm{C}$ from the $\mathrm{Ge}$ surface.

Figure 3. MSRI spectra of Ge obtained using the 74 degree reflectron analyzer following $\mathrm{N}$ exposure at $740 \mathrm{~K}$ : (A) $0.00 \mathrm{~cm}^{-2}$, (B) $5.88 \times 10^{15} \mathrm{~cm}^{-2}$, (C) $13.2 \times 10^{15} \mathrm{~cm}^{-2}$. and (D) $24.5 \times 10^{15} \mathrm{~cm}^{-2}$. 
Figure 4. Plot showing the changes in $\mathrm{H}$ (open circle - solid line), $\mathrm{C}$ (open triangle - dashed line), and $\mathrm{N}$ (filled inverted triangle - dotted line) as a function of $4.0 \mathrm{keV} \mathrm{N}$ exposure at $740 \mathrm{~K}$.

Figure 5. Plot showing the changes in $\mathrm{H}$ (open circle - solid line), $\mathrm{C}$ (open triangle - dashed line), and N (filled inverted triangle - dotted line) MSRI intensity as a function of time following the last $\mathrm{N}$ exposure $\left(24.5 \times 10^{15} \mathrm{~cm}^{-2}\right)$ at $740 \mathrm{~K}$ (spectrum D of Figure 3 ).

Figure 6 MSRI spectra obtained following heating of the $N$ exposed Ge sample (i.e, spectrum D of Figure 3) to: (A) $880 \mathrm{~K}$, (B) $810 \mathrm{~K}$, and (C) $760 \mathrm{~K}$. Heating to $\sim 880 \mathrm{~K}$ generates an atomically clean $\mathrm{Ge}$ sample; $\mathrm{H}$ and $\mathrm{C}$ redeposition commences upon cooling to $\sim 760$ K.

Figure 7. Plot showing the MSRI intensities of $\mathrm{H}$ (open circle - solid line), $\mathrm{C}$ (open triangle dashed line), and $\mathrm{N}$ (filled inverted triangle - dotted line) as a function of $4.0 \mathrm{keV} \mathrm{N}$ exposure at a Ge surface temperature of $810 \mathrm{~K}$.

Figure 8. MSRI spectra (top panel), 35 degree neutral only DRS. and 15 degree ion plus neutral DRS of a Ge sample contaminated with $\mathrm{Na}, \mathrm{Al}, \mathrm{Cr}$, and Fe. Spectra were collected following: (A) heating to $780 \mathrm{~K}$, and (B) an $\mathrm{N}$ exposure of $5.0 \times 10^{15} \mathrm{~cm}^{-2}$ at $780 \mathrm{~K}$. The absence of $\mathrm{Cr}$ and $\mathrm{Fe}$ in the 15 degree DRS is attributed to the fact that these species are subsurface (see text for discussion).

\section{REFERENCES:}

[1] O.J. Gregory and E.E. Crisman, in: Integrated Circuits: Chemical and Physical Processing of Integrated Circuits. Am. Chem. Soc. Washington, DC, 1985.

[2] J.J. Rosenberg, S.C. Martin. IEEE Electron Device Letters, 9(12) (1988) 639.

[3] A.B. Young, J.J. Rosenberg, and I Szendro, J. Electrochem. Soc 134 (1987) 2867.

[4] D.J. Hymes and J.J. Rosenberg. J. Electrochem. Soc. 135 (1988) 961.

[5] A.V. Rzhanov and I.G. Neizvestny, Thin Solid Films. 58 (1979) 37.

[6] C. Tindall and J.C. Hemminger, Surface Science 330 (1995) 67.

[7] X.H. Chen and W. Ranke. Surface Science 262 (1992) 294 
[8] W. Ranke, J. Electron. Spec. and Rel. Phenomena 61 (1993) 231

[9] W. Ranke, and J. Wasserfall, Surface Science 303 (1994) 45

[10] W. Ranke and J. Wasserfall, Surface Science 292 (1993) 10.

[11] W. Ranke, Surface Science 342 (1995) 281

[12] F. Budde, T. Gritsch, A. Modl, T.J. Chuang, and E. Ertl, Surface Science 178 (1986) 798.

[13] F. Budde, A. Modl, A.V. Hamza, P.M. Ferm, and G. Ertl, Surface Science 192 (1987) 507.

[14] A.G. Entringer, R. Shinar, H.R. Shanks, Surface Science 234 (1990) 221.

[15] W. Ranke, X.H. Chen, E. Schroder-Bergen, Vacuum 41 (1990) 656.

[16] A. Modl, H. Robota, J. Segner, W. Vielhaber, M.C. Lin, and G. Ertl, Surface Science 169 (1986) L341.

[17] X.H. Chen, and W. Ranke, Surface Science 264 (1992) 292.

[18] K. Prabhakaran, and T. Ogino, Surface Science 325 (1995) 263.

[19] D.A. Hansen and J.B. Hudson, Surface Science 292 (1993) 17

[20] D.A. Hansen, and J.B. Hudson, Surface Science 254 (1991) 222,

[21] L. Papagno, X.Y. Shen, J. Anderson, G. Schirripa Spagnolo, G.J. Lapeyre, Phys. Rev. B 34 (10) (1986) 7188.

[22] L. Papagno. D. Frankel, Y. Chen, L.S. Caputi, J.Anderson, G.J. Lapeyre, Surface Science 248 (1991) 343.

[23] C.U.S. Larsson and A.S. Flodstrom, Phys. Rev. B. 43(11) (1991) 9281

[24] C.U.S. Larsson and A.S. Flodstrom, J. Vac. Sci. Technol. A 7(3) (1989) 2044.

[25] K. Eipers-Smith. K. Waters, and J.A. Schultz, J. Am. Ceram. Soc. 76 (2) (1993) 284

[26] M.S. Hammond, J.A. Schultz, A.R. Krauss, J. Vac. Sci. Technol. A. 13 (3) (1995) 1136.

[27] V.S. Smentkowski, J.C. Holecek, J.A. Schultz, A.R. Krauss, D.M. Gruen, Rev. Sci. Instrum. in preparation

[28] W.P. Poschenrieder, Int. J. Mass Spectrom. Ion Phys. 9 (1972) 357.

[29] V.S. Smentkowski, A.R. Krauss, D.M. Gruen, J.C. Holecek, and J.A. Schultz, J. Vac. Sci. Technol. A in preparation

[30] Y.S. Chen, G.L. Miller, D.A.H. Robinson, G.H. Wheatley, and T.M. Buck, Surface Science $62(1977) 133$.

[31] A. R. Krauss, O. Auciello. and J.A. Schultz, MRS Bulletin 20 (1995)18

[32] A.R. Krauss, Y. Lin, O. Auciello, G.J. Lamich, D.M. Gruen, J.A. Schultz, R.P.H. Chang. J. Vac. Sci. Technol. A 12(4) (1994) 1943. 
[33] W.T. Taferner, A. Freundlich, A. Bensaoula, A. Ignatiev, K. Waters, K. Eipers-Smith, M. Guehenneue, and J.A. Schultz, J. Vac. Sci. Technol. A. 12 (1994) 3012.

[34] Y. Wang, H.Bu, T.E. Lytle, J.N. Rabalais, Surface Science, 318 (1994) 83

[35] L. Surnev and M. Tikhov, Surface Science 138 (1984) 40.

[36] K. Sugiyama, Y. Igari, and I. Kusunoki, Surface Science 283 (1993) 64.

[37] H.J. Kuhr and W. Ranke, Surface Science 201 (1988) 408.

[38] Private conversation, A. Bensaoula University of Houston, Space Vacuum Epitaxy Center.

[39] J.A. Schultz, unpublished results

[40] A. Benninghoven, Surface Science 299/300 (1994) 246.

[41] A. Benninghoven, Phys. Status Solid 34 (1969) K169.

[42] P. Sigmund in Sputtering by Particle Bombardment I, Springer Series Topics in Applied Physics, Vol. 47, R. Behrisch editor, (Springer Verlag: Berlin and Heidelberg, 1981) p27. 
74 degree Floating Reflectron Analyzer For MSRI/SIMS

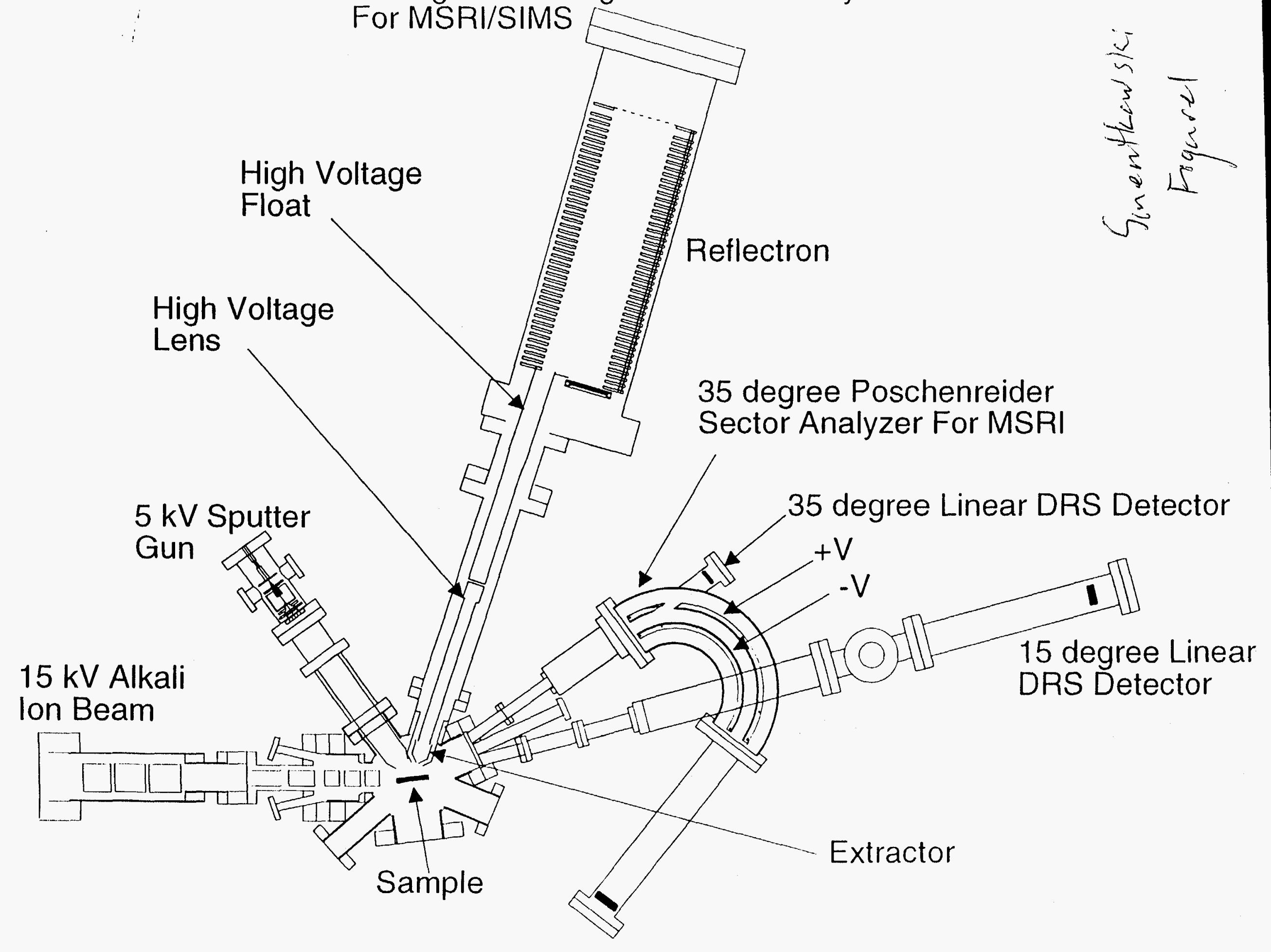


Changes in MSRI Spectra of Ge as a Function of Heating Temperature

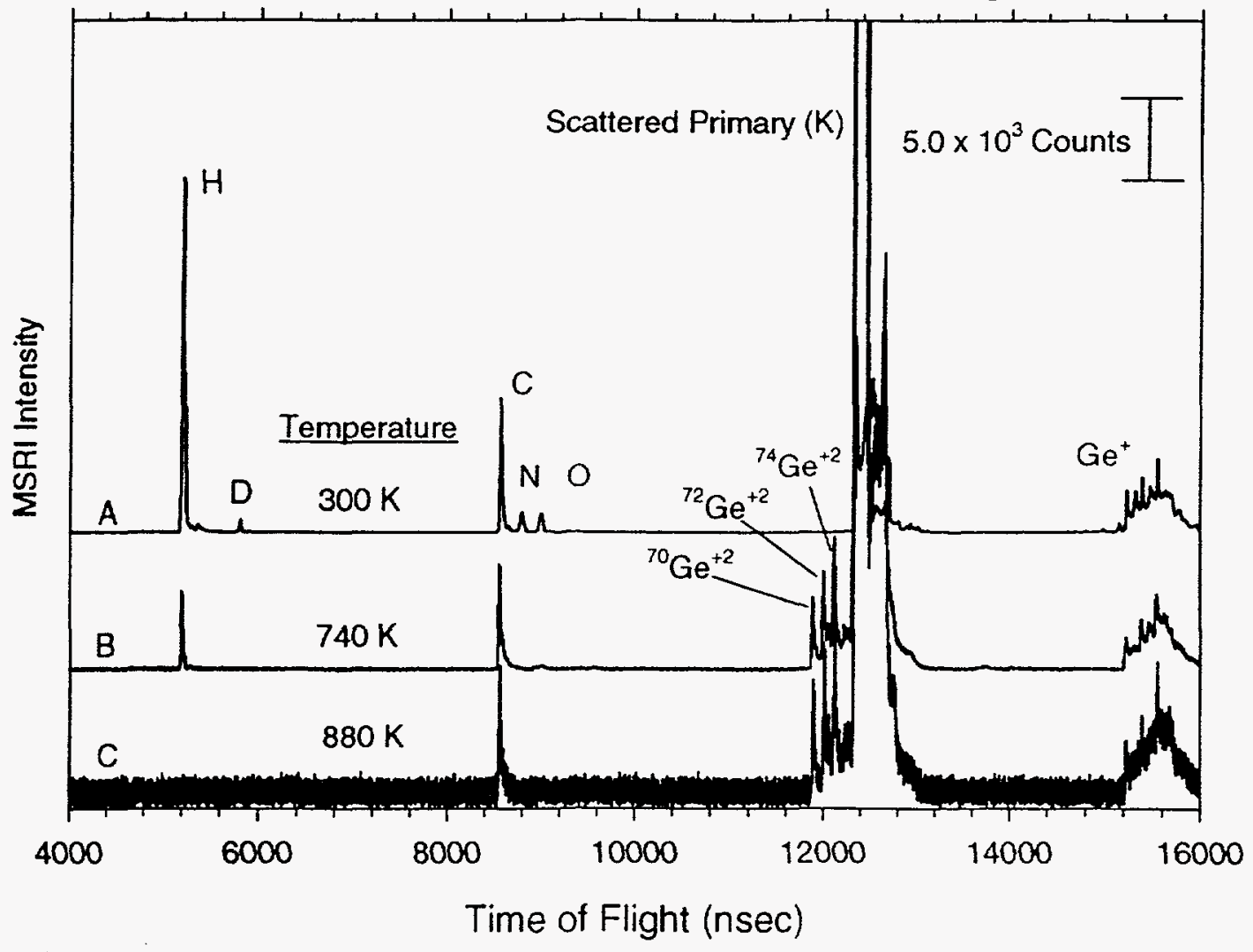

$$
\begin{gathered}
\text { Smenthariski } \\
\text { Fogure } 2
\end{gathered}
$$


Changes in MSRI Spectra of Ge as a Function of N Reactive Etching at $740 \mathrm{~K}$

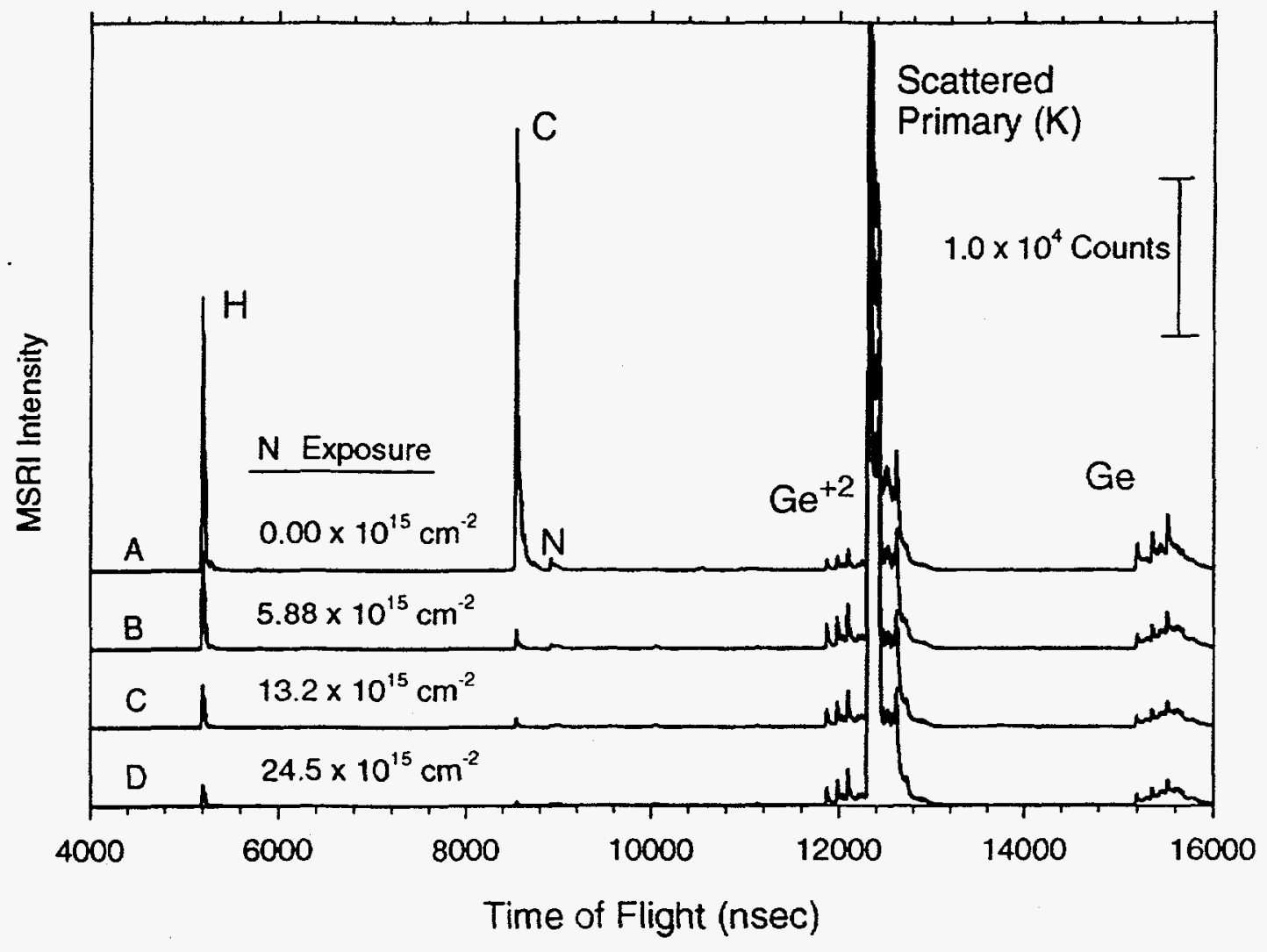

Smenthowski Figure 3 
Changes in MSRI Intensity During $4.0 \mathrm{keV} \mathrm{N}$ Exposure at $740 \mathrm{~K}$

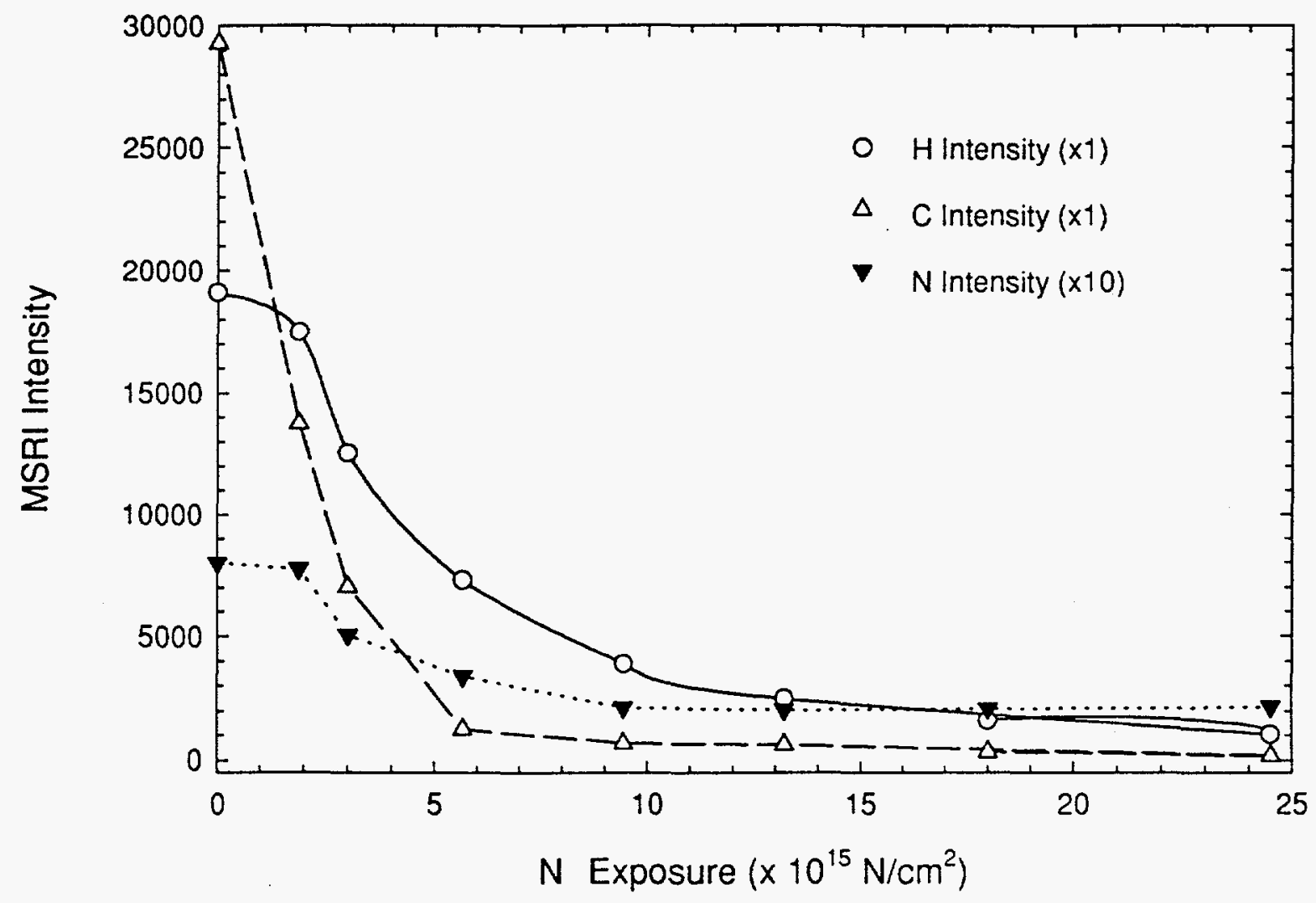

Sinentleowski
Figiney 


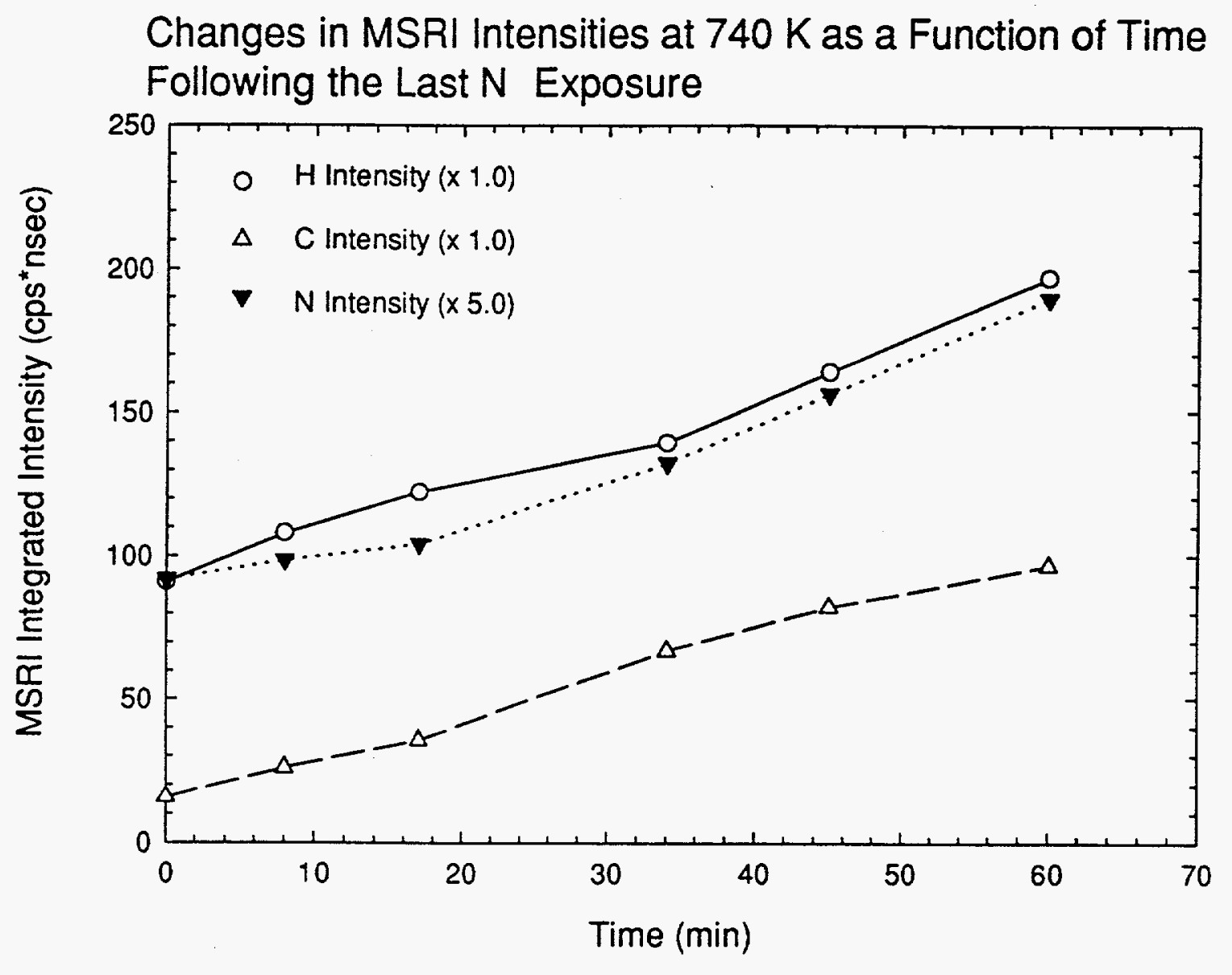

$$
\begin{aligned}
& \text { Simentlewski } \\
& \text { Figures }
\end{aligned}
$$


Changes in MSRI Spectra as Ge is Cooled Following N Reactive lon Etching

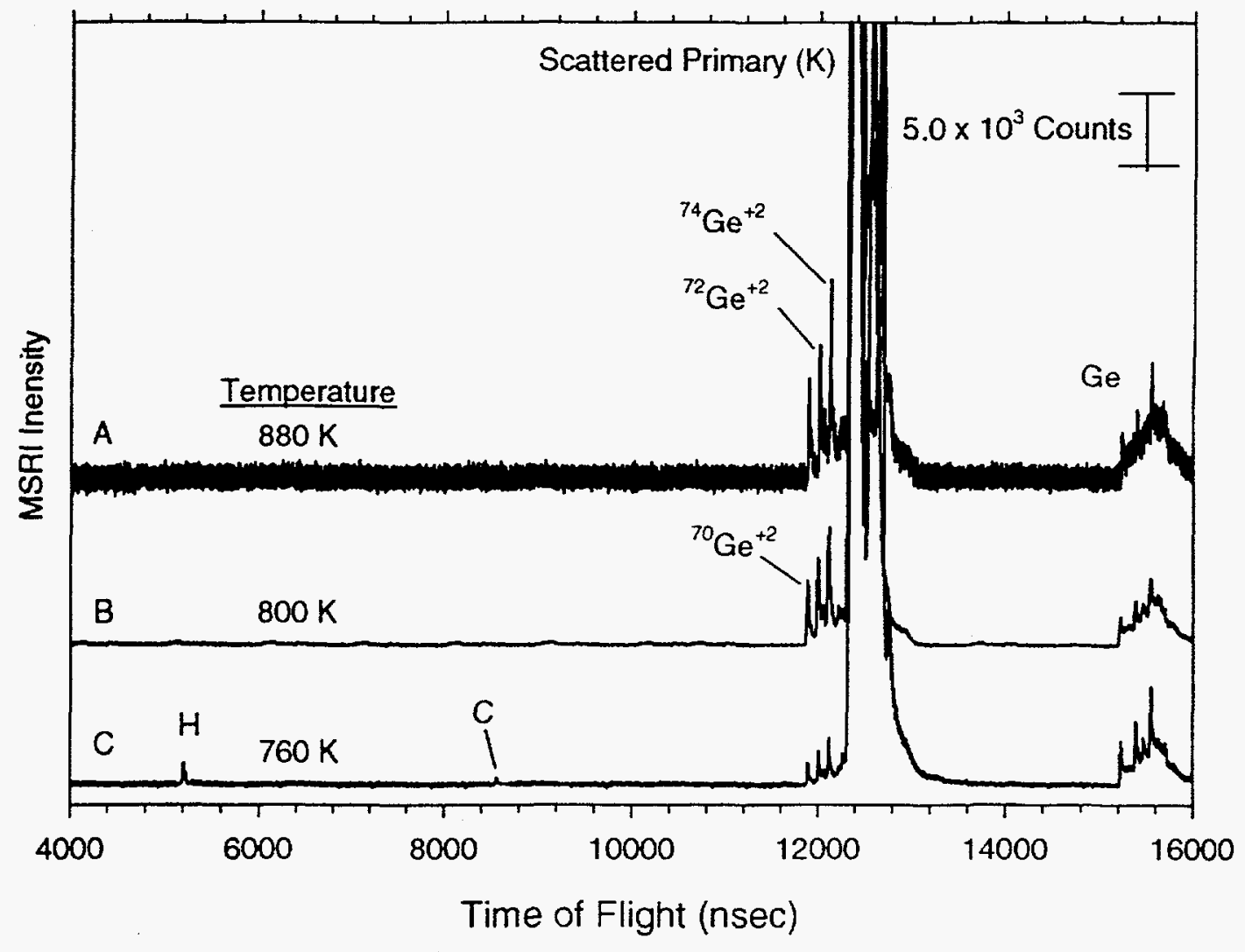

Simenttecuski

Figure 6 
Changes in MSRI Intensity During $4.0 \mathrm{keV} \mathrm{N}$ Exposure at $810 \mathrm{~K}$

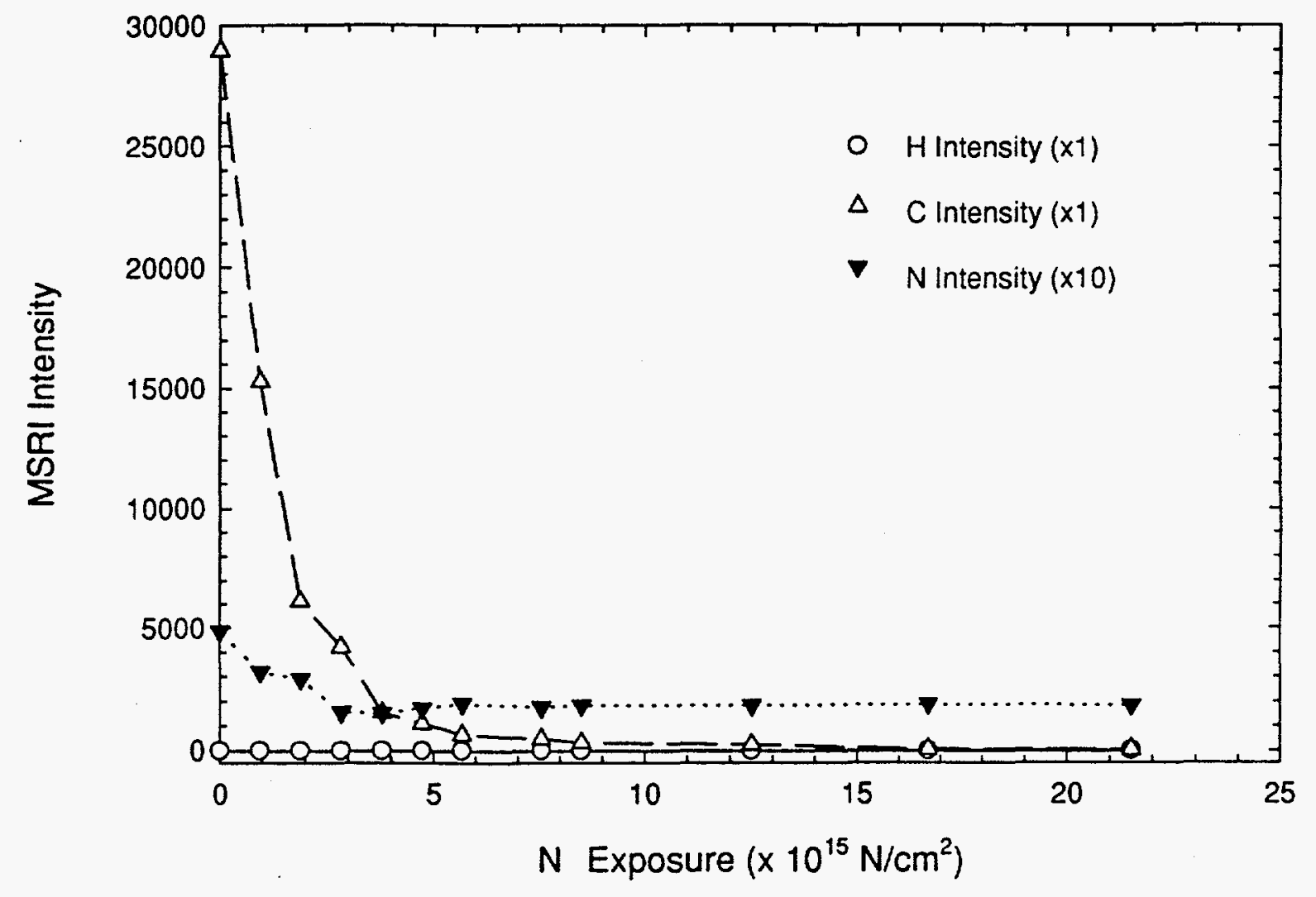

Ginenticouski Frgure 7 

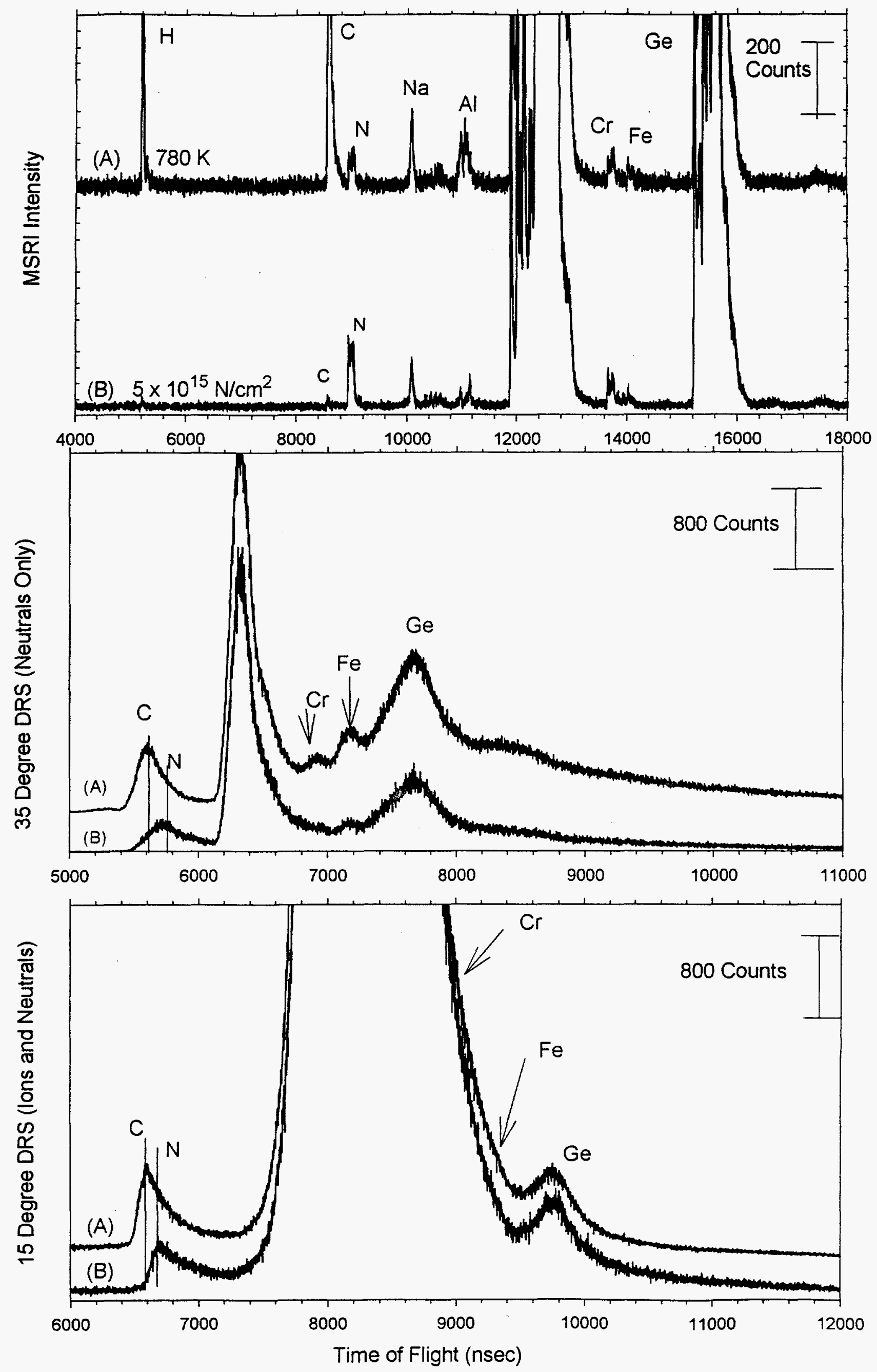